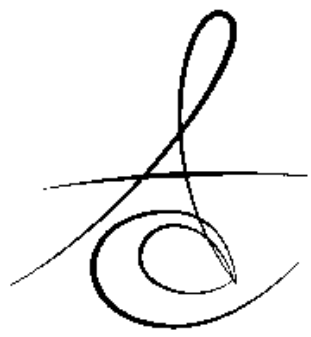

\title{
GÜNCEL DENTAL BİLGİSAYAR DESTEKLİ TASARIM/BİLGİSAYAR DESTEKLİ ÜRETİM SİSTEMLERİ
}

\section{CONTEMPORARY DENTAL COMPUTER AIDED DESIGN/COMPUTER AIDED MANUFACTURE SYSTEMS}

\author{
Dr. Bilge BEȘİR KALAYCI*
}

Prof. Dr. Funda BAYINDIR**

Makale Kodu/Article code: 1646

Makale Gönderilme tarihi: 24.04.2014

Kabul Tarihi: 21.05.2014

\begin{abstract}
ÖZET
Kırılma dayanımı yüksek seramik materyallerin üretilmesi ve bilgisayar teknolojisindeki ilerlemeler bilgisayar destekli tasarım/bilgisayar destekli üretim teknolojisinin gelişmesini sağlamıştır. Bu teknoloji hem dental laboratuvarlarda hem de dental kliniklerde, inley-onlay uygulamalarında, kron-köprü, implant abutment yapımında ve tam-ağız yapılandırılmasında kullanılmaktadır. Ayrıca CAD/CAM sistemler ortodontide de kullanılmaktadır. Birçok ileri derece geliştirilmiş chairside ve laboratuvar CAD/CAM sistemi üretilmiş veya geliştirilmektedir. Bu makale günümüz diş hekimliğinde kullanılan CAD/CAM teknolojilerine ve sistemlerine genel bir bakış açısı sağlamaktadır.
\end{abstract}

Anahtar sözcük: Bilgisayar yardımlı tasarım, bilgisayar yardımlı üretim, dental teknoloji.

\section{GİRİŞ}

Bilgisayar destekli tasarım/bilgisayar destekli üretim sistemleri 1950-1960 yıllarında endüstri alanında kullanılmaya başlandığında diş hekimliğinde de gelişmeler olacağı beklenmekteydi. İlk endüstriyel uygulamalarda, objelerin geometrileri diş hekimliğinde ihtiyaç duyulan restorasyonlara kıyasla oldukça basitti. Yine de aynı teknik dental kronların yapımı için uygulanabilirdi. Ancak bilgisayarların hesaplama gücü sınırlıydı ve bir gigabyte sürücü diye bir şey henüz duyulmamıştı ve kullanılmakta olan CAM sistemleri diş hekimliği kullanımı için oldukça büyüktü ${ }^{1}$.

Zamanla dental materyallerin estetik ve güvenilirliği ile ilgili beklentilerin artması nedeniyle;

\section{ABSTRACT}

Processing of ceramic materials with high fracture resistance and new improvement in computer technology lead to development of dental computeraided design/computer-aided manufacturing technology. The technology, which is used in both the dental laboratory and the dental clinic, can be applied to inlays, onlays, crowns, fixed partial dentures, implant abutments, and even full-mouth reconstruction. CAD/CAM systems is also being used in orthodontics. Several highly advanced chairside and laboratory CAD/CAM systems have been introduced or are under development. This article provides an overview of CAD/CAM-technologies and systems available for dentistry today.

Key word: Computer-aided design, computer-aided manufacture, dental technology

dental restorasyonların yapımı için yeni, yüksek dayanıklılığa sahip seramik materyaller geliştirilmiştir. $\mathrm{Bu}$ materyallerin konvansiyonel yöntemlerle tam uyumlu olmamaları nedeniyle de yeni üretim teknolojileri ve sistemleri geliştirilmiştir. Bunun için geliştirilen teknolojilerden birisi de bilgisayar destekli tasarım ve bilgisayar destekli üretimdir².

CAD (Computer Aided Design - Bilgisayar Destekli Tasarım); bir cismin bilgisayar sistemlerinin kullanılarak geliştirilmesi ve tasarımının yapılması anlamına gelmektedir. Bu şekilde üç boyutlu model çizimi sanal ortamda gerçekleştirilmektedir ${ }^{3}$.

CAM (Computer Aided Manufacturing Bilgisayar Destekli Üretim); ölçülen ve planlanan veriler kullanılarak bilgisayar desteği ile üretimin yapılması anlamına gelir ${ }^{3}$.

*Trabzon Ağız Diş Sağlı̆ı Merkezi, Trabzon

**Atatürk Üniversitesi Dis Hekimliăi Fakültesi Protetik Dis Tedavisi 
İlk olarak CAD/CAM sisteminin kurucusu olarak kabul edilen Francois DURET tarafindan 1971 yilında gerçekleştirilen sistemle diş hekimliğinde restorasyonların otomatik olarak yapımı gündeme gelmiştir $^{4,5}$. Heitlinger ve Rodder 1979 yilında, ardından Moermann ve Brandestini 1980'de CAD/CAM sistemleriyle ilgili çalışmalar yapmışlardır. İlk dental CAD/CAM sistemi Fransa'da 1983'te Garanciere konferansında sunulmuştur. 1985'te klinik ortamında hazırlanan, herhangi bir laboratuar işlemine tabi tutulmadan şekillendirilen ve ağızda uygulanan ilk kron protezi yapılmışıı́r.

CAD/CAM sistemleri kullanılarak hem çalışma yöntemleri basitleştirilmiş hem de daha yeni ve daha iyi materyallerin kullanılabilmesi mümkün olmuştur ${ }^{4,5}$. CAD/CAM sistemlerin geliştirilmesindeki amaç; geleneksel ölçü yöntemlerini elimine etmek, yapılacak restorasyonun doğal anatomisine, fonksiyonlarına ve preparasyonuna göre bilgisayar kullanarak tasarımını yapmak, masa başında restorasyonu üretebilmek, restorasyon kalitesini arttırmak (mekanik direnç, kenar uyumu, yüzey kalitesi) ve daha iyi bir estetik sağlamaktır?.

CAD/CAM teknolojisinin dental laboratuvar açısından bakıldığında büyük avantajları vardır. CAD/CAM teknolojisi daha kısa sürede daha yüksek kalitede otomatik fabrikasyon üretimi sağlar. Dental CAD/CAM sistemleri teknikteki hataları minimuma indirir ve klasik çok aşamalı indirekt restorasyon üretimindeki, çapraz kontaminasyon, enfeksiyon tehlikesini azaltır. Ancak CAD/CAM sistemlerinin maliyeti biraz yüksektir ve fazla miktarda ve iyi kalitede restorasyon üretiminde finansal kapasite gerektirii ${ }^{8}$.

CAD/CAM sistemleri ile ilgili yapılan bir sınıflama makine destekli üretimin, klinikte ya da laboratuvarda gerçekleştirilmesine göre yapılmaktadır. Restorasyon klinikte direkt olarak diş hazırlığı ile aynı seansta üretilirse, bu "chair-side concept" olarak isimlendirilir. Direkt yöntemin avantajı tüm işlemin tek seansta tamamlanması dolayısıyla zamandan tasarruf sağlamasıdır. Eğer yöntem diş laboratuvarı işlemi gerektirirse bu "lab-side concept" olarak ifade edilir. Laboratuvarda kullanılan sistemin avantajı bu cihazların farklı işlemlerde kullanılabilmesidir ${ }^{4,5}$.

CAD/CAM sisteminde, prepare edilen dişin görüntüsü intraoral veya extraoral olarak taranarak bilgisayar ortamına aktarımakta ve bilgisayar programı kullanılarak restorasyonun tasarımı yapılmaktadır. Tasarlanan restorasyon, önceden üretilen seramik blokların bilgisayar ile uyumlu çalışan bir makinede şekillendirilmesi ile elde edilmektedir ${ }^{9,10}$.

Alümina ve zirkonya esaslı seramikler gibi yüksek dirence sahip seramiklerin sadece CAD/CAM sistemleri ile üretilebilmesi bu sistemlere olan ilgiyi arttırmıştır $^{11}$. Y-TZP tam seramik restorasyonların üretiminde de CAD/CAM sistemleri kullanılmaktadır ${ }^{12}$. Ayrıca titanyum alaşımları ${ }^{13}$ gibi farklı alaşımlar da CAD/CAM sistemlerinde kullanılabilir.

Kullanılan ilk CAD/CAM sistemlerinde, blok şekillendirilirken aşındırmanın iki eksende yapılmasından dolayı diş ile restorasyon arasında iyi bir uyum sağlanamamıştır. Yapılan çalışmalar sonucunda günümüzde altı eksende aşındırma yapabilen sistemler geliştirilmiştir ${ }^{14}$.

CAD/CAM teknolojisi kullanılarak, zirkonya alt yapıların üretiminde iki önemli teknik bulunmaktadır. Birincisi yüksek yoğunlukta sinterlenmiş hazır bloklardan nihai boyutta alt yapının oluşturulmasıdır. Önceden sinterlenmiş bu blokların frezelenmesi oldukça fazla zaman almakta ve aynı zamanda işleyen cihazın frezlerinde aşınmaya ve malzemenin mikro yapısında çatlak oluşumuna neden olmaktadır. Bu prosedürle işlem yapan Denzir (Cadesthetics $A B$ ) ve DC-Zirkon (DCS Dental AG) olmak üzere iki sistem bulunmaktadır.

CAD/CAM sistemindeki ikinci teknikte restorasyon homojen bloklardan freze edilerek oluşturulmakta ve genellikle sinterlenmemiş (ham gövde) veya önceden yarı sinterlenmiş blokların cihaz tarafından işlenmesi ile elde edilmektedir. Freze edilen alt yapılar daha sonra sinterlenmekte, böylece arzu edilen boyutuna büzülerek ulaşmaktadır ${ }^{15,16}$.

\section{CAD/CAM Komponentleri}

Tüm CAD/CAM sistemleri 3 fonksiyonel komponent içermektedir:

\section{Tarayıcı (Scanner)}

Sistemin bilgi toplayan parçasıdır. Diş hekiminin yaptığı diş preparasyonunu, komşu dişleri ve okluzyondaki dişlerin geometrisini intraoral ya da ekstraoral olarak tarar ${ }^{10,11}$.

Temelde iki farklı görüntüleyebilme seçeneği vardır:

a) Optik tarayıcı

Bu tarayıcı seçeneğinin temelinde triangulasyon prosedürü diye isimlendirilen yapıların üç boyutlu

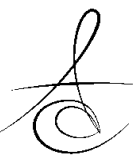


görüntüsünün elde edilmesi vardır. Beyaz ışık, renkli ışık ya da lazer projeksiyonu kullanılarak güdük üzerinden optik tarama yapılır. Işık kaynağı ve reseptör ünite birbirleriyle uygun açıda yerleşmelidir. Optik tarayıcıların çoğu harekete duyarlıdır. Bu nedenle optik tarayıcılar ile veri toplanırken, hastanın oluşturduğu en ufak hareket bile, verilerin hatalı kaydedilmesiyle sonuçlanabilmektedir. Hızlı ve yüksek çözünürlükte verilerin elde edilmesi optik tarayıcıların avantajlarıdır. Birçok CAD/CAM sisteminde tarayıcı, sistemin bir parçasıdır ve yalnızca uygun CAD yazıımı ile çalışmaktadır ${ }^{11}$.

\section{b) Mekanik tarayıcı}

Mekanik tarayıcıda iğne ucu, küre ya da pin kullanarak güdük üzerinden mekanik tarama yapılır. $\mathrm{Bu}$ görüntülemede ana modelin mekanik olarak üç boyutlu ölçümü yapılır.

Yüzeyin taranarak verilerin elde edilmesi aşaması CAD/CAM sistemleri arasında farklılık göstermektedir (Tablo I) ${ }^{17}$.

Tablo 1. Farklı CAD/CAM sistemlerinin tarayıcı özellikleri ${ }^{16}$.

\begin{tabular}{|c|c|c|c|c|}
\hline \multirow{3}{*}{$\begin{array}{c}\text { CAD/CAM } \\
\text { Sistemi }\end{array}$} & \multicolumn{4}{|c|}{ Dijital Okuma } \\
\hline & \multirow[t]{2}{*}{ Mekanik } & \multicolumn{3}{|c|}{ Optik } \\
\hline & & $\begin{array}{c}\text { Ekstra } \\
\text { oral }\end{array}$ & \begin{tabular}{|c} 
İntra- \\
oral
\end{tabular} & $\begin{array}{c}\text { Işık } \\
\text { Kaynağı }\end{array}$ \\
\hline Lava@ & & + & & Beyaz ışık \\
\hline ce. novation & + & + & + & Rastgele \\
\hline $\begin{array}{l}\text { Pro } 50^{\mathrm{TM}} \text {. } \\
\text { WaxPro }\end{array}$ & & + & & Beyaz ışık \\
\hline DCS Precident $®$ & & + & & Lazer \\
\hline DECIM & & + & & Lazer \\
\hline $\begin{array}{l}\text { Cercon } ® \text { smart } \\
\text { ceramics }\end{array}$ & & + & & Lazer \\
\hline Perfactory ${ }^{\circledR}$ & + & + & + & Görünür ışık \\
\hline $\begin{array}{l}\text { Bego } \\
\text { Medifacturing }\end{array}$ & & + & & Beyaz ışık \\
\hline Etkon & & 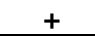 & & Lazer \\
\hline GN-I & & + & & Lazer \\
\hline diGident & & + & & Beyaz ışık \\
\hline $\begin{array}{l}\text { ZFN-Verfahren, } \\
\text { Xawex } \\
\text { Dentalsystem }\end{array}$ & & + & & Lazer \\
\hline Everest $₫$ & & + & & Beyaz ışık \\
\hline Celay® & Kopyalama & & & \\
\hline Procera $®$ & + & & & \\
\hline Triclone 90 & + & & & \\
\hline CEREC $\circledast$ & & + & + & Beyaz ışık \\
\hline EDC® & & + & & Lazer \\
\hline WOL-CERAM & & + & & Lazer \\
\hline ATLANTIS & & + & & Lazer \\
\hline
\end{tabular}

\section{Dizayn Yazılımı (Software)}

Bilgisayar ekranında restorasyonun üç boyutlu dizaynı ve planlamasının yapılabilmesi için bir bilgisayar ünitesi içerir. Kişiye özgü adapte edilmiş restorasyonun dizaynına ve üretilmesine izin veren bir çok yazııım programı geliştirilmiştir. Kullanıcı CAD yazılımında bulunan şablonları direkt kullanabileceği gibi, modifikasyonlar oluşturarak kendi tasarımını da yapabilmektedir. Yazılım programları genellikle CAD/CAM sistemine özgüdür ve diğer sistemlerle uyumluluk göstermemektedir. Restorasyonun tasarımı tamamlandığında, CAD yazıımı sanal modeli farklı bir formata dönüştürerek CAM ünitesinin üretime geçmesini sağlamaktadır ${ }^{11}$.

\section{Donanım (Hardware)}

Bilgisayar kontrolünde olan frezleme ve aşındırma makinelerini ifade eder. Restorasyon, materyal bloklarından frezlenerek elde edilir. Kural olarak CAM üretiminden sonra bazı manuel düzeltmeler, final cilalanmalar, renklendirmeler ve porselen uygulamaları diş teknisyeni tarafından yapılır ${ }^{10,11}$.

\section{Güncel CAD/CAM Sistemleri}

Günümüzde kullanılan CAD/CAM sistemleri üretim metodlarına göre üç gruba ayrılırlar:

1. Direkt klinikte kullanılan sistemler; İntraoral olarak diş preparasyonunu tarar ve restorasyon klinikte hazırlanır.

\section{$>$ Cerec}

Sirona (Sirona Dental Systems $\mathrm{GmbH}$, Bensheim,Germany), hem klinikte hem de laboratuvarda kullanılan sistemlere sahip tek üreticidir. CEREC ilk olarak 1985 yılında kullanılmaya başlanmış olup, geliştirilen ilk CAD/CAM sistemidir. 1994 yılında CEREC 2, 2000 yılında CEREC $3^{18}, 2014$ yılında CEREC SW 4.2.4. piyasaya sürülmüştür ${ }^{19}$. CEREC $3 D$, ağız içi kameranın ağızda sabit tutulmasıyla ayak pedalı yardımıyla görüntünün yakalanmasını sağlarken, CEREC AC (Resim 1) ile bu işlem daha da geliştirilerek kamera ağızda sabit olarak tutulduğunda sistemin otomatik olarak görüntüyü yakalaması sağlanmıştır. CEREC AC ile preperasyonun dijital ölçüsü, intraoral tarayıcı kamerayla direkt olarak hasta ağzından alınır. Görüntünün alınabilmesi için özel bir toz sprey diş yüzeyine uygulanmalıdır. Alınan görüntü dosyaları direkt kameranın bağlı olduğu bilgisayara transfer edilir. CEREC, uygun tasarımı kesilmiş diş üzerine komşu dişlere uygun şekilde yerleştirir. Yaratıcı 


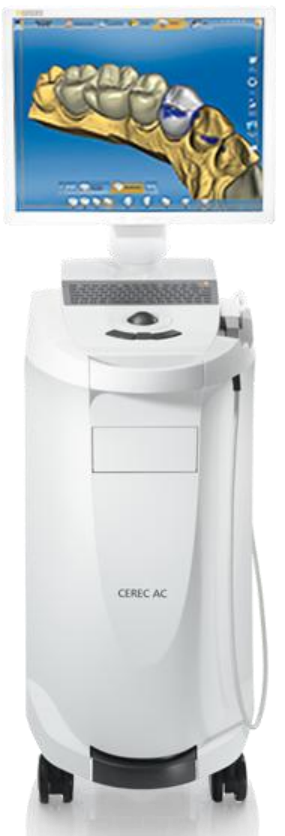

Resim 1. Cerec AC, ağız içi kamera ve tasarımın yapıldığı yazılım.

özelliğiyle hastanın mevcut dişlerine benzer morfolojide restorasyon tasarlama özelliği bulunmaktadır. Bu şekilde her bireye özel, kendi dişlerine benzer restorasyon yapılabilmektedir. Bu aşamadan sonra hekim istediği değişiklikleri yapar; karşıt dişle olan kontakt noktalarını kontrol edebilir, sanal olarak aşındırma, ekleme, kontür değişikliği yapabilir, komşu dişlerle kontakt noktalarının sıkılığını arttırıp azaltabilir. Yazılıma bağlı olarak daha birçok değişikliğin yapılması mümkündür. Son çıkan ve kullanımı daha kolay olan 4.0 yazılımıyla, bir hastada yapılacak tüm restorasyonlar aynı anda tasarlanabilmektedir. Tasarım bittikten sonra, uygun renk ve boyutta seçilen blok MC XL freze cihazıyla (Resim 2) freze edilerek, tek seansta restorasyon bitirilir. CEREC sistemiyle kullanılabilen bloklar feldspatik ve lösitle güçlendirilmiş cam seramikler olduğu gibi, lityum disilikat gibi yüksek dirence sahip seramikler, nano seramikler ve geçici amaçla kullanılan blokları da içermektedir.

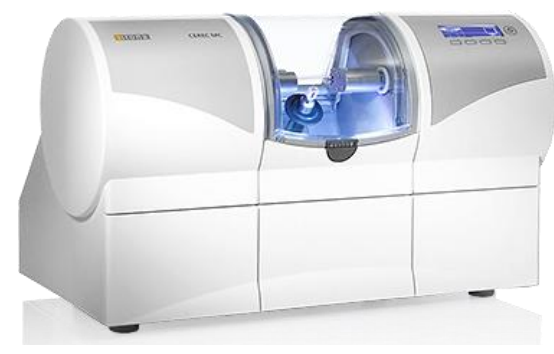

Resim 2. Cerec MC freze cihazı.

Klinikte kullanılan CAD/CAM sistemlerinin avantajı dijital ölçünün alınmasını takiben tasarımın ve üretimin hastanın yanında gerçekleştirilebilmesi, işlemin bu nedenle hızlı olmasıdır. Ayrıca hastaların klinikte son teknoloji cihazlarının bulunduğunu görmeleri, klinikte hekimin prestijini arttırmakta ve olumlu yönde hastaları etkilemektedir. Maliyetinin yüksek olması sistemin dezavantajıdır ${ }^{20}$.

\section{$>$ E4D Dentist}

2005 yllında piyasaya sürülen E4D Dentist sistemi (Resim 3), yansıtıcı toz olmadan intra-oral lazer tarayıcı (IntraOral Digitizer) ile diş preparasyonu tarayabilmektedir. Hekim birçok açıdan görüntü alarak veri noktalarını arttırır, böylece yazılım doğru morfolojiyi bilgisayarda oluşturabilir.

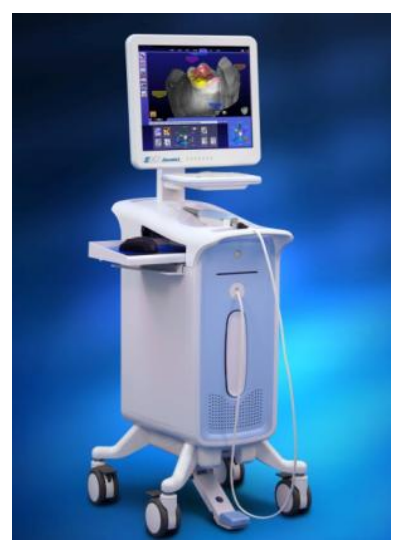

Resim 3. E4D Dentist

Sistemin ekranında 3 boyutlu görüntüler yumuşak ve sert doku olarak ayırt edilmekte, kronların çevresi ve ağız içi ortamın netliği görülmektedir. Aynı anda 16 üyeye kadar restorasyon tasarımı yapılabilen DentaLogic yazılımına sahip olan cihazın otomatik oluşturma özelliğiyle anatomik yapılara uyumlu kişisel tasarım yapılmaktadır.

E4D Dentist firmasının online ücretsiz yazılım güncellemesi yapması bu sisteme ilave avantaj sağlamaktadır. Fakat kullanılabilecek malzeme çeşitliliğinin fazla olmaması sistemin dezavantajıdır.

Lösitle güçlendirilmiş seramik bloklar, lityum disilikat bloklar, nanoseramik ve geçici amaçla kullanılan bloklar E4D Dentist sistemi ile uyumludur ${ }^{20}$.

2. Laboratuvarda kullanılan sistemler; Alçı modelden veya ölçüden tarama yapılmaktadır. Bu sistemlerin çoğunda alt yapı üretilir, ve teknisyen restorasyonu karakterize edebilmek için üzerine porselen uygular. 


\section{$>$ CEREC inLab}

2004 yılında laboratuvar kullanımı için üretilmiştir. Lazer tarayıcı (inEos Blue) ile çalışma modelin dijital görüntüsü alınır. Sistemin inEos Blue kısml; tarayıcl, bilgisayar ve inLab 3D tarayıcl-tasarım yazııımını içermektedir (Resim 4). InEos Blue kısmının dışında frezeleme ve sinterleme cihazı da sistemde bulunmaktadır. Tasarım yazılımında bulunan patentli "biogeneric" özelliği ile hastanın mevcut dişlerine benzer morfolojide restorasyon yapılabilir. Bu şekilde yazılımda mevcut standart diş şekilleri değil, bireysel olarak her hastaya uygun morfolojide restorasyon yapılabilmektedir.

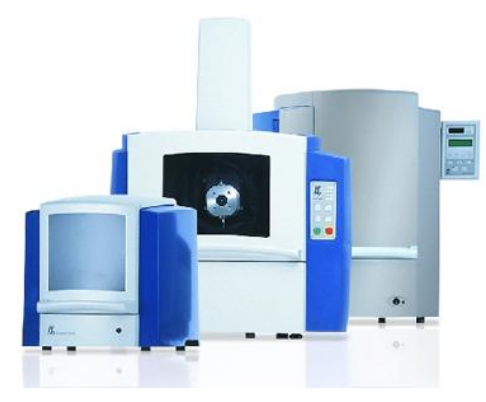

Resim 5. Everest sistemi

Tasarım bittikten sonra inLab MC XL frezeleme cihazıyla restorasyon hazırlanır. Bu cihaz $\pm 25 \mu$ hassasiyetle çalışmakta ve 10 üyeye kadar köprü frezeleyebilmektedir. Günde 40-60 üye restorasyon yapılabilir. Sinterleme fırını olan inFire HTC Speed ile beş üye köprü 90 dakikada sinterlenebilmektedir.

CEREC inLab sisteminin diğer bir özelliği de zirkonya köprü alt yapılarıyla beraber üzerine kullanılacak porseleni de freze ederek, daha sonra bu iki parçanın birbiriyle birleştirilmesine olanak vermesidir. Bu şekilde elle yapılan porselen yığımı yerine, alt yapıyla tam uyumlu ve oklüzal morfolojisi cihazın CAD kısmıyla önceden belirlenmiş olan üst yapı hazırlanı ${ }^{21}$.

CEREC inLab sistemi için Sirona, Vident, Ivoclar Vivadent ve 3M Espe firmalarının ürettiği çeşitli bloklar mevcuttur.

\section{$>$ DCS Preci-fit}

DCS Preci-fit sistem, 1990 ylında kullanılmaya başlanmıştır. Cam seramik, metal, güçlendirilmiş seramikleri freze etmesinin yanısıra, restorasyon alt yapılarını tam sinterlenmiş bloklardan (DC-Zirkon) ve titanyumdan da (DCTitan) hazırlayabilen az sayıda CAD/CAM sisteminden bir tanesidir ${ }^{22}$. Sistem, Preciscan lazer tarayıcı ve Precimill frezeleme makinesini içermektedir. DCS Dentform yazııımı köprülerde gövde şekillerini ve konnektör boyutlarını otomatik olarak tasarlamaktadır.

\section{$>$ Cercon}

Dentsply firmasına ait olan, 2002 yilında piyasaya sürüldüğünde sadece CAM sistemi olarak çalışan sistem, 2005 ylında sisteme üç boyutlu optik tarayıcı (Cercon eye) ve Cercon Art CAD tasarım yazılımı eklendikten sonra CAD/CAM sistemi olmuştur. Her bir üye 20 saniyeden kısa sürede, 10 mikron hassasiyetle taranabilmektedir. Kron kenarları otomatik olarak belirlenir. Cercon brain expert ile frezeleme, Cercon heat plus ile sinterleme yapılmaktadır. Tek üyeden 9 üyeye kadar yarı sinterlenmiş zirkonya blokları freze edebilir. 16 üyeye kadar köprü sinterlemesi yapılabilmektedir.

\section{$>$ Everest}

Kavo firması tarafından üretilmektedir. Sistem; tarayıcı (Everest Scan), aşındırma ünitesi (Everest Engine), sinterleme firını (Everest Therm) ve bu üniteler arası koordinasyonu sağlayan ve tasarımın yapııdığı bilgisayardan oluşur (Resim 5). Tarayıcı ile alçı model dönen tablaya yerleştirilir ve CCD (Charge Coupled Device) kamerayla taranır. Taranan modelin üç boyutlu dijital hali bilgisayarda oluşturulur. Tek üye kron restorasyonun tasarlanması beş dakikada tamamlanabilir. Tasarımı takiben frezelemeye geçilir. Aşındırma ünitesinin beş eksende frezeleme özelliği bulunmaktadır.

Everest sistemiyle inley, onley, anterior ve posterior kron, köprü yapılabilmektedir.

\section{$>$ Zeno Tec System}

Wieland firmasının 2005 yılında piyasaya çıkarttığı sistem, üç boyutlu lazer tarayıcı, sinterleme fırını, freze makinesi ve vakumu içermektedir. Zirkonya blokların yanısıra, titanyum ve Cr-Co köprü alt yapıları da işlenebilmektedir. Sistemin küçük-orta ve orta-büyük ölçekli laboratuvarlara göre çeşitli tarayıcı ve freze cihazları mevcuttur.

\section{> Katana Sistemi (Noritake Dental, Aichi, Japonya)}

Katana sistemi tarama cihazı (SC-3), freze ünitesi [DWX-30N(4-axis) ve DWX-50N (5-axis)] ve sinterleme fırınından oluşmaktadır. Sistem sadece sinterlenmemiş Y-TZP bloklarını işlemektedir. Freze ünitesinin üç üyeli bir sabit bölümlü protezi üretmesi $30-45 \mathrm{dk}$ sürmektedir. Sinterleme işlemi $1400^{\circ} \mathrm{C}^{\prime} \mathrm{de}$ gerçekleşmekte ve sonrasında $\% 21$ oranında

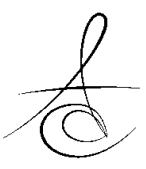


sinterleme büzülmesi görülmektedir ${ }^{23}$.

Katana sisteminin bloklarından biri olan Alliance zirkon bloklar, diğer CAD/CAM sistemlerinden farklı olarak renkli Y-TZP bloklardır. 4 farklı renk seçeneği bulunan sistemin avantajı blokların renklendirilmesi için ek bir işlem gerektirmemesidir. Alt yapı hazırlandıktan sonra sistemin uyumlu olduğu Noritake CZR veya CZR Press seramikleriyle restorasyon tamamlanmaktadır ${ }^{24}$.

3. Üretim merkezli CAD/CAM sisteminde ise, model laboratuvarda tarandıktan sonra veriler internetten ana üretim merkezine gönderilir. Alt yapısı hazırlanan restorasyon, üzerine porselen eklenmesi için laboratuvara geri gönderilir. Tüm alt yapıların aynı merkezde yapılmasıyla optimal kalite kontrolü sağlanır ${ }^{8}$.

\section{$>$ Procera}

Nobel Biocare tarafindan 1994 yilında piyasaya sürülmüştür. Alumina ile yüksek hassasiyette kron alt yapıları, veneer ve abutment'lar yapılabildiği gibi, zirkonyadan abutment, kron-köprü alt yapısı da yapılabilmektedir. Öncelikle modelin 20.000 ölçüm noktası veren taraması yapilır. Laboratuvara kurulan kompakt bir tarama cihazıyla alçı modelin taraması bittikten sonra elde edilen veriler internet yardımıyla New Jersey/ABD veya İsveç'te bulunan üretim merkezine gönderiliir ${ }^{15}$. Üretim merkezinde seramiğin büzülmesini kompanse edebilecek büyüklükte genişletilmiş day'lar hazırlanır. Genişletilmiş day üzerinde hazırlanmış ve sinterlenmiş alt yapılar üzerine, porselen uygulaması ve bitim için alt yapılar tekrar teknisyene gönderilir ${ }^{25}$.

Procera AllCeram sisteminde CAD/CAM teknolojisi kullanılarak yoğun olarak sinterlenmiş, saf ve yüksek dayanıkllıkta alüminyum oksit (\%99.5) alt yapılar üretilmektedir ${ }^{26}$. Ayrıca zirkonyumoksit alt yapııı restorasyonlar (Procera AllZirkon), titanyum alt yapilı restorasyonlar (Procera AllTitan), titanyum veya alüminyum oksit abutmentlar, implant üstü tam seramik kronlar ve implant üstü titanyum köprü alt yapılarının üretimi mümkündür ${ }^{27}$.

\section{$>$ Lava}

2002 yilında 3M ESPE tarafindan piyasaya sürülmüştür. Sistemde Lava Scan ST optik tarayıcı, Lava CNC 240 veya 500 frezeleme makineleri ve Lava Furnace 200 sinterleme firını bulunmaktadır (Resim 6). Kron-köprü alt yapıları üretim merkezlerinde hazırlanabilir. Bilgilerin dijital hale getirilmesi için optik tarama sistemi kullanılmaktadır.

Lava sistemi otomatik olarak kron kenarlarını ve gövdenin oturacağı yeri belirler. Yapılacak alt yapı sinterleme büzülmesini kompanse edebilmek için \%2025 büyük tasarlanır. Yarı sinterlenmiş zirkonya bloklar kullanıı.ı. Tasarım sonrasında restorasyon uygun boyuttaki bloklardan freze edilir. Her blokta barkod numarası bulunur ve uygun bloğun barkodu okunduktan sonra frezelemeye başlanır. Tek üye alt yapı 15 dakika, üç üye köprünün frezelenmesi yaklaşık 45-50 dakika sürmektedir.

Sinterleme öncesi yedi farklı seçenekte renklendirme yapılabilir. Bu işlem frezeleme sonrasında restorasyonun renklendirici solüsyona batırılmasıyla yapıır. Böylece alt yapının üst yapı porseleni ile daha iyi uyum göstermesi ve estetiğin artması sağlanır ${ }^{28}$.

\section{Manuel Tasarım/Manuel Üretim (MAD/MAM-Manual Aided Design-Manual Aided Manufacturing)}

Zirkonya alt yapı, MAD-MAM (Manual Aided Design-Manual Aided Manufacturing) prensibi ile elde tasarım ve kazıma yapılarak da üretilebilir. Seramiğin direkt işlenmesi, zirkonyadan yapılan yarı sinterlenmiş poroz yapıdaki blokların aşındırılarak genişletilmiş alt yapıların şekillendirilmesi esasına dayanmaktadır. Şekillendirme sonrası tüm kitle sinterlenmekte ve homojen bir büzülme göstermektedir ${ }^{14}$.

Bu prensip ile çalışan sistemler mevcuttur:

1. Zirkonzahn (Zirkonzahn GmbH, Bruneck, İtalya)

2. Ceramill (Amann Girrbach $\mathrm{GmbH}$, Österreich, Avusturya)

\section{$>$ Zirkonzahn}

Zirkonzahn (Steger, Ahrntal, İtalya) sistemi ile hem CAD/CAM hem de MAD/MAM (Manuel Aided Design/ Manuel Aided Manufacturing) yöntemiyle üretim yapılabilmektedir. MAD/MAM yönteminde, alçı model üzerinde restorasyon yapılacak diş ya da dişlerin alt yapı tasarımı, firmanın kendi ürettiği ışıkla sertleşen kompozit rezin ile yapllır. Restorasyonun şekillendirilebilmesi için kompozit dizayn, makinenin okuyucu ucunun bulunduğu tarafa, Zirkonzahn blok ( ICE Zirkonia veya Prettau) ise aşındırma işleminin yapılacağı tarafa yerleştirilir. Okuyucu frez, teknisyen tarafından hazırlanan kompozit alt yapı üzerinde manuel olarak hareket ettirilirken, kesici frez, zirkonya blok üzerinde susuz ortamda restorasyonu şekillendirir ${ }^{29}$. 
Hacim olarak \%20 daha büyük hazırlanan restorasyon, istenilen rengin elde edilebilmesi için renklendirici solüsyonlar ile renklendirildikten sonra yaklaşık $1500^{\circ} \mathrm{C}^{\prime}$ de 16 saat süre ile sinterlenir ve orijinal boyutuna ulaşır. Üst yapı seramiği uygulanması sisteme uyumlu bir düşük ISI seramiği (ICE Ceramic) ile gerçekleştirilmektedir ${ }^{29}$.

Zirkonzahn, maliyetinin düşük olması sebebiyle birçok laboratuvar tarafından tercih edilmektedir. Alt yapı dizayn edilirken bir tarayıc tarafından modellerin taranması gerekmez. Bu nedenle andırkat bulunan ve paralel olmayan kesimlerde, diğer sistemlere göre daha rahat restorasyon hazırlanabilir.

\section{$>$ Ceramill}

Ceramill sistemi pantografi cihazı (Ceramill Multi-x) (Resim 7) ve sinterleme fırınından (Ceramill Therm) oluşmaktadır. Bu sistemde de alt yapı tasarımı manuel olarak yapılmaktadır. Bu amaçla sistemin kron ve gövde tasarımı için iki farklı akışkanlığa sahip jel şeklinde ışıkla sertleşen modelaj malzemeleri (Ceramill Gel ve Ceramill Pontic) bulunmaktadır. Alt yapı tasarımı bu jellerle yapıldıktan sonra sistemin özel ışık cihazı (Ceramill UV) ile sertleştirilmektedir. Freze işlemi okuyucu bir ucun hazırlanan alt yapı tasarımını okuması ve buna uygun olarak aşındırıcı uçların yarı sinterlenmiş Y-TZP blokları (Ceramill Zi) şekillendirmesi şeklinde gerçekleşmektedir. Sinterleme işlemi $1450^{\circ} \mathrm{C}^{\prime}$ de yapılmaktadır. Beş farklı renk ile renklendirilebilen alt yapılara mevcut bütün feldspatik seramikler uygulanabilmektedir ${ }^{30}$.

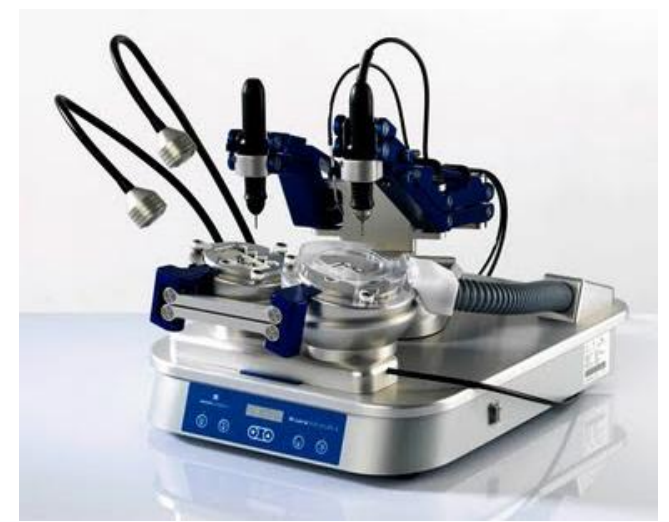

Resim 7. Ceramill Multi-X.

\section{SONUÇ}

Günümüzde kullanılan CAD/CAM sistemlerinin değişik materyal kullanımına uyumlu olmaları ve farklı parametrelerin kontrolünde kolaylık (tabaka kalınlığı, kavite şekli, siman kalınlığı gibi) sağlamaları gibi bir çok avantajları vardır. Bu sistemlerle elde edilen restorasyonların materyal kalitesi ve yüksek uyumluluğu beklentileri karşılayacak şekilde sağlanabildiği için, daha kaliteli restorasyonlar yapılabilmektedir. CAD/CAM sistemlerinin avantajlarının yanında bazı sınırlamaları da bulunmaktadır. Henüz hiçbir sistem geleneksel yöntemler ile elde edilen bir restorasyonu tam olarak üretme yetisine sahip değildir. Gelecekte teknolojinin de ilerlemesi ile CAD/CAM sistemlerinin eksiklikleri giderilip, cihaz ücretlerinin ayarlanmasıyla CAD-CAM teknolojisinin, dental restorasyonların üretiminde rutin uygulamalardan biri olacağı öngörülebilir.

\section{KAYNAKLAR}

1. Rekow ED. Dental CAD/CAM systems: a 20-year success story. J Am Dent Assoc. 2006;137:5-6.

2. McMillian P. Glass-Ceramics. 2. edition. London; Academic Press; 1979.

3. Jedyrakiewicz N, Martin N. Cerec science, research and clinical application. Compend Contin Educ Dent. 2001;22:7-13.

4. Hickel R, Dasch W, Mehl A, Kremers L. CAD/CAM-fillings of the future. Int Dent J. 1997;47:247-58.

5. Mehl A, Hickel R. Current state of development and perspectives of machine-based production methods for dental restorations. Int J Comput Dent.1999;2:9-35.

6. Duret $F$, Blouin JL, Duret B. CAD-CAM in dentistry. J Am Dent Assoc. 1988;11:715-20.

7. Christensen GJ. Computerized restorative dentistry. State of the art. J Am Dent Assoc. 2001;132:13013.

8. Liu PR. A panorama of dental CAD/CAM restorative systems. Compend Contin Educ Dent. 2005;507-8.

9. Raigrodski AJ. Contemporary materials and technologies for all-ceramic fixed partial dentures: a review of the literature. J Prosthet Dent 2004;92:557-62.

10. Tinschert J, Natt G, Hassenpflug S, Spiekermann $\mathrm{H}$. Status of current CAD/CAM technology in dental medicine. Int J Comput Dent. 2004;7:25-45. 
11. Strub JR, Rekow ED, Witkowski S. Computer-aided design and fabrication of dental restorations: current systems and future possibilities. J Am Dent Assoc. 2006;137:1289-96.

12. Luthardt RG, Holzhuter MS, Rudolph $H$, Herold V, Walter MH. CAD/CAM-machining effects on Y-TZP zirconia. Dent Mater. 2004;20:655-62.

13. Uzun İH, Bayındır F. Dental uygulamalarda titanyum ve özellikleri. Atatürk Üniv. Diş Hek. Fak. Derg. 2010;20:213-20.

14. Mormann WH, Bindl A. All-ceramic, chair-side computer-aided design/computer-aided machining restorations. Dent Clin North Am. 2002;46:405-26.

15. Att W, Grigoriadou M, Strub JR. ZrO2 three-unit fixed partial dentures: comparison of failure load before and after exposure to a mastication simulator. J Oral Rehabil. 2007; 34:282-90.

16. Miyazaki T, Hotta Y, Kunii J, Kuriyama S, Tamaki Y. A review of dental CAD/CAM: current status and future perspectives from 20 years of experience. Dent Mater J. 2009;28:44-56.

17. Ersu B, Yüzügüllü $B$, Canay Ş. Sabit Restorasyonlarda CAD/CAM Uygulamaları. Hacettepe Üniv Diş Hek Fak Derg 2008;32:58-72.

18. Mörmann $W H$, Brandestini $M$. The fundamental inventive principles of CEREC CAD/CAM. In: Mörmann WH. State of the art of CAD/CAM restorations. 20 years of CEREC. Berlin; Quintessence: 2006.

19. Cerec online. Cerec sw 423 update [online]. http://www.cereconline.com [Accessed 14 April 2014].

20. Çelik G, Üşümez A, Sarı T. Bilgisayar destekli diş hekimliği ve güncel CAD/CAM sistemleri. Cumhuriyet Dent J 2013;16:74-82.

21. Rekow ED, Silva NR, Coelho PG, Zhang Y, Guess P, Thompson VP. Performance of dental ceramics: challenges for improvements. J Dent Res. 2011;90:937-52.

22. Liu PR, Essig ME. Panorama of dental CAD/CAM restorative systems Compend Contin Educ Dent. 2008;486-8.

23. Kuraray Noritake Dental Inc. (2013) Katana CAD/CAM system [online]. Available from: http://www.noritake-dental.co.jp/katana/ system/system.html [Accessed 15 April 2013].
24. Turkuaz Dental. Alliance Zirkonya Blok Broşür[online].http://turkuazdental.com/download/ pdf/alliance_brochure.pdf [Accessed 15 April 2013].

25. Andersson M, Oden A. A new all-ceramic crown. A dense-sintered, high-purity alumina coping with porcelain. Acta Odontol Scand. 1993;51:59-64.

26. Conrad HJ, Seong WJ, Pesun IJ. Current ceramic materials and systems with clinical recommendations: a systematic review. J Prosthet Dent 2007;98:389-404.

27. Ural Ç. Diş hekimliği pratiğinde tamamı seramik ve Cad/Cam uygulamaları. Dirim Tıp Gazetesi 2011;86:27-38.

28. Piwowarczyk A, Ottl P, Lauer HC, Kuretzky T. A clinical report and overview of scientific studies and clinical procedures conducted on the 3M ESPE Lava All-Ceramic System. J Prosthodont. 2005; 14:39-45.

29. Technology HZ. Zirkonzahn product catalog [online]. Avaible from: http://www.zirkonzahn. com/assets/files/kataloge/EN-Catalogue-productsCADCAM-web.pdf. [Accessed 15 April 2013].

30. AmannGirrbach Gmbh. Ceramill brochure [online]. Avaible from: http://www.amanngirrbach. com/fileadmin/_agweb/media/downloads/Prospekt e/Mall/Ceramill_Mall_GB.pdf. [Accessed 15 April 2013].

\section{Yazışma Adresi}

Prof. Dr. Funda BAYINDIR

Atatürk Üniversitesi,

Diş Hekimliği Fakültesi, Protetik Diş Tedavisi AD

Erzurum, Türkiye

Tel.: 044223609 44-1779, e-mail: bayindirf@atauni.edu.tr 